\title{
VITRALES: \\ PATRIMONIO ARTÍSTICO CULTURAL DE LAS IGLESIAS DE LA ARQUIDIÓCESIS DE SAN JOSÉ DE COSTA RICA
}

\author{
Luis Carlos Bonilla Soto \\ Universidad Estatal a Distancia \\ Seminario Nacinal Nuestra Señora de los Ángeles
}

Recibido: 7-12-2016

Aprobado: 25-03-2017

\section{RESUMEN}

Licenciado en Sociología por la Universidad de Costa Rica. Investigador en los departamentos de Arte Sacro y de Piedad Popular de la Curia Metropolitana de San José. Docente en la Cátedra de Sociología de la Universidad Estatal a Distancia y en el Seminario Nacional Nuestra Señora de los Ángeles.

Icbonillasoto@gmail.com

Se explora el panorama amplio de las obras artísticas, en soporte de vitral, existentes en los templos católicos de las Temporalidades de la Arquidiócesis de San José. Este artículo responde a un esfuerzo de sistematizar la información referente a los vitrales, con el fin de abrir vetas de análisis sobre la cultura material existente en las iglesias católicas en Costa Rica.

Palabras clave: vitrales - iglesias de Costa Rica - patrimonio cultural.

\section{ABSTRACT}

The wide panorama of artistic works is explored in support of stained glass, that exist in the Catholic churches in the properties of the Archdiocese of San Jose.

This article responds to an effort to systematize the information about the stained glass windows, in order to open a lode of analysis of the existing physical culture in Catholic churches in Costa Rica.

Keywords: stained glass windows - churches in Costa Rica - cultural heritage.

\section{INTRODUCCIÓN}

Los vitrales, desde su invención como técnica artística y de ornamentación arquitectónica, han adquirido distintas funciones en las edificaciones.

En el caso de las iglesias, inmuebles donde esta técnica nació y desde donde se ha desarrollado a lo largo de los siglos, los vitrales tienen múltiples funciones, que van desde su rol como componente 
arquitectónico (ventanales), hasta la ornamentación y embellecimiento de los espacios a partir de los juegos de colores, condicionados estos últimos por la dinámica de la luz a lo largo de un día y por las escenas o temas representados en cada uno de ellos. Asimismo, han jugado un rol preponderante, al igual que las otras manifestaciones del arte plástico como la pintura y la escultura, en la trasmisión de los mensajes de fe y la aprehensión de los dogmas afirmados por el cristianismo. Estas funciones primordiales se han visto acompañadas de funciones sociales, tales como, asentar identidades comunitarias, ser vehículos que permiten dar estatus social a un individuo o un grupo y remembrar a alguna persona o colectivo que ha realizado en la historia parroquial, o de la comunidad de fe, un esfuerzo pastoral considerable.

En los siguientes párrafos se expondrá sobre el acervo artístico en vitrales que dispone la Arquidiócesis de San José en el territorio que comprende dentro de la nación costarricense ${ }^{1}$.

No se pretende abordar a profundidad aspectos técnicos de las obras, que de por sí son complejos y dan para estudios específicos, más bien, lo que se pretende es describir, a partir de variables cuantitativas, las ubicaciones - tanto territorial como dentro de los espacios litúrgicos de los templos- la procedencia y las casas fabricantes, así como las temáticas de los 416 vitrales inventariados por el Departamento de Arte Sacro y Ambientación Litúrgica de la Curia Metropolitana de san José entre el 2007 y el 2013.

Es decir, se hará referencia a todas las obras de esta índole ubicadas en todas las iglesias dispuestas bajo la tutela de las Temporalidades de la Arquidiócesis de San José, pues el fin del artículo es poner en evidencia, la existencia de una cultura material eclesiástica muy vasta que se ofrece para ser indagada. Se busca, asimismo, presentar un panorama amplio de este tipo de bienes, por lo que se abarcaran todos los años en los que estos fueron instalados, es decir, a partir de 1902 y que permanecen bajo la custodia de dicha diócesis.

\footnotetext{
${ }^{1}$ La Arquidiócesis comprende ochenta y una parroquias en la provincia de san José, veintitrés en la provincia de Heredia y cinco en la de Cartago.
} 
Además, para evitar parcializaciones subjetivas sobre el valor o no valor de las obras, se retratará la generalidad, por tanto las referencias comprenderán vitrales de diversas épocas, casas fabricantes, calidades de materiales y dibujo.

Aunque se tienen registrados otros vitrales con motivos cristianos dentro de los lindes de la arquidiócesis, como son los diez de manufactura española situados en la iglesia del convento de san Antonio de Guadalupe, los situados en la casas de las religiosas Bethleminas y de los padres carmelitas en San Pedro, los de la iglesia Don Bosco y el de manufactura costarricense situado en el Seminario Nacional Nuestra Señora de los Ángeles, estos no entran dentro de la población a estudiar por el criterio de tutela jurídica de los bienes ${ }^{2}$.

Se realizará una breve reflexión con miras a plantear algunas razones (sin ansias de aseverar con contundencia) de por qué imperan ciertas temáticas sobre otras y su relación con el espacio que ocupan.

Metodológicamente, a partir de las fichas de inventario de bienes culturales que dispone el departamento de Arte Sacro de la Curia Metropolitana, quien redacta estas líneas levantó una base de datos que concentra algunas variables referentes a las cualidades de los vitrales estudiados. Por tanto, la información recabada en sitio y las 2628 fotografías del acervo construido por el departamento mencionado, así como los datos aportados por el trabajo de investigación de Rodolfo Gutiérrez Cerdas y Santiago Quesada Vanegas del Centro de Investigación y Conservación del Patrimonio Cultural, del Ministerio de Cultura, Juventud y Deportes (2005), en el que se ficharon 298 obras, son el insumo fundamental para abordar el patrimonio eclesiástico en cuestión.

\footnotetext{
2 Existe por otra parte, un vitral con el tema del Buen Pastor con san Lucas y san Andrés en la iglesia episcopal Good Shepard sobre avenida 4ta, que es digno de referencia.
} 


\section{LOS VITRALES COMO PATRIMONIO CULTURAL DE LA IGLESIA}

En la carta emitida por la Pontificia Comisión para los Bienes Culturales de la Iglesia, se afirma que el patrimonio cultural eclesiástico abarca de manera destacada las expresiones tangibles que la Iglesia Católica ha adquirido a lo largo de los siglos, por ello, sobre la definición de patrimonio afirma:

(...) es el bien cultural de interés religioso en cuanto objeto, es decir, en cuanto obra producida por el hombre, visible, mensurable, deteriorable. Esta obra está dotada de una apreciable dimensión de representación religiosa, de modo que asume el valor de un bien cultural eclesial. (Pontificia Comisión para los Bienes Culturales de la Iglesia, 2003: 71)

Ante esto se tiene que el arte sacro, como manifestación plástica de la fe, comprende un amplio patrimonio cultural en buen número de países en los que los procesos de evangelización e implantación de una lógica de cristiandad, han afectado todas las esferas de la vida social. En el caso de Costa Rica, este abarca una buena parte del acervo artístico, pues la centralidad conferida a esta institución religiosa provocó y continúa provocando una atención particularísima, tanto de los fieles más comprometidos con la fe, así como de quienes asisten a los oficios religiosos por tradición familiar, organizacional o por los beneficios por parte del estado con el que, durante muchos años, ha mantenido una relación tan estrecha ${ }^{3}$.

Por consiguiente, en el momento de investigar este tipo de bienes, no es viable desvestir la obra artística, destinada a un fin sagrado, de la vivencia de evangelización y de la celebración de la fe, que de una u otra forma se ha vinculado con otras esferas de la vida socio-política y cultural para permearlas de la doctrina que la Iglesia profesa, pues:

\footnotetext{
${ }^{3}$ Incluso en momentos de tensión estado-iglesia, como fue la promulgación y ejecución de leyes anticlericales, existió vinculación entre ambas parte para la construcción de iglesias. Al respecto se tiene que "En la década de 1890, la dirección General de Obras Públicas sufrió una nueva reestructuración, fortaleció su departamento técnico y dejó en manos de la empresa privada la edificación de obras nacionales, mediante concursos por licitación pública. Pero, aunque el diseño de los nuevos planos fue contratado en forma privada, estos fueron ejecutados, en gran parte, por personas allegadas a esa dirección. Por ejemplo, el ingeniero Lesmes Jiménez, quien había sido director de la Dirección de Obras Públicas, participó en los diseños de las iglesias de San Isidro y San Rafael en Heredia, y en la de La Merced y la de Moravia, en San José" (Fonseca y Garnier, 1998: 265)
} 
A través de estos bienes se despliega la acción pastoral de la Iglesia dando continuidad y perspectiva a la vida eclesial. Son cultural y espiritualmente significativos en el ámbito de la comunidad cristiana que les ha producido y en la oferta a la fruición de aquellos que entran en contacto con ellos. Consecuentemente, no se pueden considerar aislados del conjunto al que pertenecen y deben subordinarse a la misión de la Iglesia. (Pontificia Comisión para los Bienes Culturales de la Iglesia, 2003: 76)

\section{DISTRIBUCIÓN TERRITORIAL DE LAS OBRAS ARTÍSTICAS}

En treinta y cuatro iglesias se albergan cuatrocientos dieciséis vitrales, ciento diecisiete en seis iglesias de la provincia de Heredia, el resto en veintiocho iglesias localizadas en la provincia de san José.

Este patrimonio se ha caracterizado por ingresar a las iglesias en Costa Rica en un momento de progreso económico, que coincide en gran medida por la consolidación del cultivo del café (Zamora, Álvarez y Vives, 2002: 32). Todo esto en medio de la construcción de procesos para conformar el estado-nación, en los cuales el desarrollo de las exportaciones de café se acompañan de la consolidación de centros de población, distribuidos políticamente en cantones.

Por ejemplo, no es casual que las iglesias de San Rafael, San Isidro y Santo Domingo (las tres ubicadas en las cabeceras de los cantones con estos mismos nombres en Heredia), alberguen un total de 80 vitrales, ya que la erección de estas parroquias y creación políticoadministrativa de los respectivos cantones donde estas se ubican, está asociada al auge económico que se dio a partir de la producción cafetalera y el consiguiente crecimiento poblacional". "Durante las décadas que siguieron al establecimiento de la exportación a Europa, el cultivo se extendió rápidamente a través de la Meseta Central, hasta que, en 1889, 'toda la Meseta desde Cartago a Alajuela estaba

\footnotetext{
${ }^{4}$ La parroquia de Santo Domingo de Heredia fue erigida el 23 de agosto de 1854 (Sanabria, 1933: 256), el cantón del mismo nombre fue creado el 28 de septiembre de 1869. La parroquia de San Isidro de Heredia fue erigida el 26 de diciembre de 1881 (Archivo Histórico Arquidiocesano. Fondos Antiguos, documentación encuadernada caja $N^{\circ} 185$ Exp. No 45 de 36 folios) y la fundación del cantón de San Isidro de Heredia el 13 de julio de 1905. Asimismo, la parroquia de San Rafael de Heredia fue erigida el 3 de julio de 18861881 (Parroquia San Rafael de Heredia, 1986: 6) y el cantón del mismo nombre fundado el 28 de mayo de 1885.
} 
cubierta con cafetales'" (IFAM, 2003: 9) Y, el crecimiento de estos poblados llegó incluso a superar en número a pueblos con asentamientos más antiguos como lo es Barva (Ruiz, 2004).

En dichos poblados, aquellas personas y familias que gozaban de mayor riqueza y ejercían el poder político y económico, aportaron sumas mayores para la erección de las nuevas iglesias parroquiales, que vinieron a sustituir las edificaciones previas en el lapso que va desde finales del siglo XIX hasta la primera mitad del siglo XX. Siendo en los templos construidos en dicho periodo donde el número de vitrales para cada inmueble supera los veinte ventanales.

En el cuadro $N^{\circ} 1$ se puede mirar el listado de las iglesias y la cantidad de vitrales en cada una de ellas. Con esto se puede constatar cómo son las iglesias parroquiales ubicadas en las cabeceras de cantón donde el número de vidrieras es superior y corresponden a sitios de culto erigidos en los pueblos que incrementaron su bonanza a partir de las plantaciones cafetaleras.

Si se analiza la asociación entre la instalación de los vitrales y el diseño de las iglesias erigidas a finales del siglo XIX e inicios del S XX, el estilo de estos inmuebles se inspira en el neogótico y el neoclásico.

\section{Cuadro $\mathrm{N}^{\circ} 1$}

Distribución de vitrales según iglesia

Arquidiócesis de San José, 2014

(Cifras absolutas)

\begin{tabular}{|c|c|}
\hline Vicaría Foránea & $\begin{array}{c}\text { Núm } \\
\text { ero } \\
\text { de } \\
\text { Vitral } \\
\text { es }\end{array}$ \\
\hline San Vicente Ferrer de Moravia & 42 \\
\hline Nuestra Señora de la Soledad, San José* & 40 \\
\hline Catedral Metropolitana de San José (Casa francesa)** & 42 \\
\hline Santo Cristo de Esquipulas, Alajuelita & 29 \\
\hline San Rafael Arcángel, Heredia & 28 \\
\hline Nuestra Señora de los Desamparados & 26 \\
\hline
\end{tabular}


San Isidro Labrador, Heredia $\quad 26$

Santo Domingo de Guzmán, Heredia 26

San Pedro Apóstol, Montes de Oca $\quad 22$

Inmaculada Concepción, Heredia 20

Santa Teresita, B ${ }^{\circ}$ Aranjuez 16

Nuestra Señora del Carmen, Heredia 14

Nuestra Señora de la Merced, San José 12

La Natividad de la Virgen María, La Uruca ${ }^{\star \star \star}$

San Francisco de Asís, Tabarcia $\quad 8$

Nuestra Señora de Guadalupe 8

Sgdo. Corazón de Jesús, Hatillo

San Antonio de Escazú $\quad 7$

Capilla Sagrario - Catedral Metropolitana (Casa alemana) 6

San Isidro Labrador, Coronado 5

Santa Catalina de Alejandría, La Uruca 3

Inmaculada Concepción de María, Zapote 3

San Rafael Arcángel, Heredia (Casa alemana) 3

Templo Votivo al Sagrado Corazón, San José 2

Nuestra Señora del Perpetuo Socorro, Sabana Sur 2

San Ignacio de Loyola, Acosta 2

Nuestra Señora del Carmen, San José 1

Nuestra Señora de Fátima. Hatillo 3

Medalla Milagrosa, Quebrada Honda, Patarrá 1

San Miguel Arcángel, Desamparados 1

Nuestra Señora de Loreto, Rohrmoser 1

Inmaculada Concepción, Pozos 1

San Martín de Coronado $\quad 1$

Inmaculada Concepción, Korobó 1

San Francisco de Asís, Dos Ríos 1

Total $\quad 416$

* Se tiene conocimiento de la existencia de dos vitrales de la iglesia de la Soledad en San José, que no fueron instalados y se encuentran guardados en la casa cural, por lo cual el número exacto de obras en esta edificación sería 42 , pero por no estar fichados y desconocer más detalles sobre estos, se parte de la cifra expuesta en la celda.

** El situado en la puerta que comunica la Sacristía con la capilla se desconoce su procedencia, pero se incluye en este número. 
*** Estos vitrales estuvieron ubicados en la capilla del antiguo Seminario Central de San José, situado una cuadra al este de la Catedral Metropolitana. El conjunto se encuentra incompleto, algunos vitrales se hallan en territorio diocesano de Alajuela.

Fuente: Elaboración propia.

El vitral, como soporte artístico, es impropio del lenguaje barroco dominante en las edificaciones coloniales. Desde dicho periodo histórico hasta el presente, la ornamentación mueble ha estado asociada a otras técnicas, siendo privilegiadas en estas tierras las obras escultóricas confeccionadas por imagineros, buen número manufacturadas por costarricenses (de los que tanto se desconoce y por consiguiente a los que tanto se les resta autoría) y por obras que se trajeron de España, Guatemala y México.

Las iglesias josefinas y las iglesias parroquiales heredianas erigidas en el periodo liberal, dan un salto de paradigma en la introducción de otro soporte para las representaciones de los pasajes evangélicos y del santoral católico, pues el formato de vidrio incorporado, si bien no se asoció a las prácticas devocionales de veneración que sí ostentan aún las imágenes escultóricas, se potenció para dar sentido de belleza a los espacios rituales y atraer la atención de las personas presentes. Incluso en las iglesias de mayor antigüedad, como la Inmaculada Concepción de Heredia edificada a partir 1797, se instalaron vitrales que, en el caso de la parroquia del centro herediano, proceden de Francia ${ }^{5}$.

El salto no se restringe a una cuestión meramente formal en cuanto a la opción de colocar vitrales en las iglesias, pues esto se inserta en la lógica del imaginario social que busca generar un parteaguas con la época colonial anterior, en donde lo europeo no ibérico se posiciona como el modelo a imitar en el estilo de vida de las élites que definieron la estética de la nueva infraestructura de uso público, siendo las iglesias un espacio en el que se dio de una u otra manera esta injerencia.

\footnotetext{
${ }^{5}$ Estos vitrales perdieron piezas originales y las mismas fueron sustituidas con otras de deficiente calidad que permiten distinguir con facilidad el cambio.
} 


\section{PROCEDENCIA Y CASAS FABRICANTES}

Indiscutiblemente, la llegada de las vidrieras está asociada a los nexos que algunos sacerdotes de la época tenían, principalmente por su lugar de origen y por la facilidad de contacto, en los países en los que se sitúan las casas fabricantes.

El nexo más fácilmente detectable es el de los padres de la Congregación de la Misión o padres paulinos, quienes irradiaron la vida pastoral arquidiocesana inicialmente desde el Seminario Central. No es casualidad que los doce vitrales que se reubicaron en la iglesia parroquial de la Natividad de la Virgen María en la Uruca, hayan sido adquiridos para ser instalados en la capilla del antiguo Seminario Mayor, otrora ubicado en el cuadrante este de la Catedral Metropolitana en la década de 1930, al igual que los que se adquirieron para la capilla del Sagrario de la Catedral, que proceden de Linnich, Alemania, de la casa vitralista Dr. H. Oidtmann Glasmalerei.

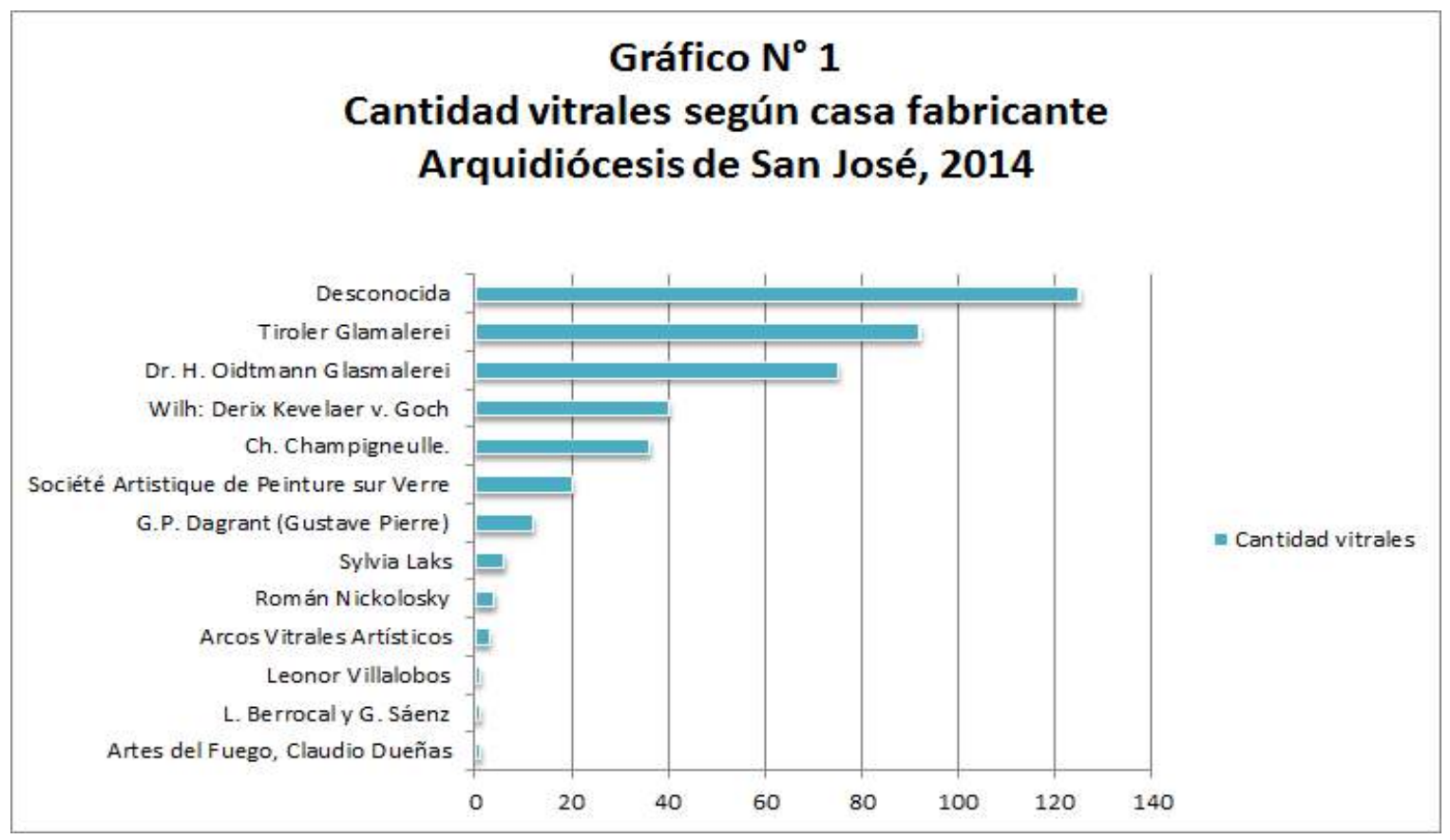

Fuente: Elaboración propia. 
En el gráfico $\mathrm{N}^{\circ} 1$ se visualizan las casas fabricantes de los conjuntos de vitrales de las iglesias en cuestión.

De los 125 vitrales que se desconoce la casa fabricante, se tiene que 29 son de origen francés. Lo que reafirma que los países de procedencia preponderantes son: Alemania con 115 obras, Austria con 94 y Francia con 92.

Las dos casas fabricantes de las que se adquirieron mayor número de vidrieras son la Tiroler Glasmalerei situada en Austria y la del Dr. H. Oidtmann Glasmalerei situada en Alemania. La primera fue fundada en 1861 y, según la reseña histórica que la empresa aporta en la actualidad, se menciona a Costa Rica como uno de los principales países a donde se exportaron obras ${ }^{6}$. La segunda fue fundada por el Dr. Heinrich Oidmann en 1857 y desde su origen las distintas generaciones que le sucedieron han asumido la dirección de la empresa. Ambas fábricas se encuentran activas hasta la fecha y han obtenido distintas menciones y medallas en ferias y exposiciones en esta materia.

En el caso costarricense la vitralista que mayor número de obras ha incorporado en sitios de culto de la Arquidiócesis de san José es Silvia Laks, destacándose el ubicado en el Templo Votivo al Sagrado Corazón de Jesús, en barrio Francisco Peralta, pues es el más grande de todos, con una superficie de doscientos diecisiete metros cuadrados.

\footnotetext{
${ }^{6}$ El estudio de Gutiérrez y Quesada aportan la traducción realizada por Miki Bors de las reseñas
} históricas de las casa fabricantes que aparecen en los sitios web de cada una de ellas. 


\section{DONANTES}

El papel del mecenas no ha estado ausente en este tema. En cuarenta y ocho de los cuatrocientos dieciséis vitrales figuran los nombres de treinta y cuatro personas y cinco agrupaciones donantes ${ }^{7}$.

\section{Cuadro $\mathbf{N}^{\circ} 2$}

\section{Cantidad de vitrales con inscripción del donante según tipo de donación (Cifras absolutas)}

\begin{tabular}{lc} 
Colectivo & 11 \\
\hline Persona & 37 \\
\hline $\begin{array}{l}\text { Total } \\
\text { general }\end{array}$ & $\mathbf{4 8}$ \\
\hline
\end{tabular}

Fuente: Elaboración propia.

El que se observen cuarenta y ocho vitrales en los que se hace alusión directa a las o los donantes, no significa que otros también fueran a su vez donados, no obstante sin la alusión a la persona o agrupación directa la tarea de identificarlos se torna más difícil, pues la información recopilada en las fichas, tanto de las confeccionadas desde la Curia Metropolitana como del Ministerio de Cultura y Juventud, no logran brindar datos adicionales, por lo que se evidencia la necesidad de mayor recuperación de datos y en la profundización en la revisión documental para completar la información básica de las mismas.

En el caso de los vitrales en los que aparecen los nombres de las personas donantes y dicho nombre corresponde con el nombre del santo o santa, queda en evidencia que la donación está en la línea de destacar al patrono por el cual se puso el nombre de pila o del nombre del poblado de quien dio el dinero para la adquisición, esto se observa en dos vitrales de la parroquia de Tabarcia de Mora: uno hace alusión a san Víctor, cuyo nombre es el mismo del donante y a Nuestra Señora de los Ángeles, cuyo vitral lo donó el caserío del mismo nombre, situación similar sucede con san Bruno, san Francisco, san

\footnotetext{
7 Incluyen los que indican en "memoria de" o "recuerdo de", los que aparecen dos nombres y los que indican un nombre al que se le suma "Señora" "y familia".
} 
Antonio y san Simón en la iglesia de san Rafael de Heredia. Asimismo, la intención del donante en algunos casos está asociada a la devoción y tramitación de favores, como es el caso del tema de la Virgen del Carmen para pedir por las almas de los difuntos. Esta relación que se podría vislumbrar entre los temas y los donantes, lo que lleva a pensar es en la necesidad social existente de recordar y fijar el nombre de personas y momentos para la posteridad que, en el formato de arte en vidrio esto puede realizarse por medio de un retrato, un nombre, una devoción específica que defina el tema y el recordatorio de quien realizó la donación económica para adquirirlo ${ }^{8}$.

\section{TEMÁTICAS}

En los temas tratados en los vitrales se pueden distinguir tres vertientes: 1. figurativo de santos y santas; 2 . escenas bíblicas y 3 . diseños ornamentales (principalmente con motivos geométricos y fitomorfos).

En el caso de las dos primeras vertientes temáticas se puede determinar a quienes se dirigen dichas obras. En la primera - sobre las representaciones de santos - se tiene como destinatario al pueblo piadoso, pues las estampas devocionales se trasladan al vidrio. Por su parte, las representaciones de pasajes bíblicos se pueden agrupar en dos tipos: por un lado las que están asociadas a la función ritual de los espacios que ornamentan, tal es el caso de los vitrales que representan el Bautismo del Señor situados cerca de los baptisterios, y los otros de pasajes de muy diversa índole que remiten al observador a un relato, pero para ello quien observa requiere de conocimientos bíblicos de distinto nivel, pues no todos los pasajes representados conectan fácilmente con los textos de la Sagrada Escritura a los que hacen referencia, debido a que algunos son más conocidos y accesibles que otros en la transmisión popular de los soportes bíblicos de la fe católica.

8 En dos vitrales de San Pedro de Montes de Oca aparece el retrato de Monseñor Rubén Odio para recordar la consagración de la iglesia parroquial y, en el vitral del Tránsito de San Benito en Santo Domingo de Heredia, aparece retratado el pbro. Benito Sáenz. El vitral del Corazón de Jesús en Alajuelita fue donado por el pbro. Enrique Kern, siendo él fue uno de los principales difusores de esta devoción en Costa Rica. 


\section{Gráfico $\mathrm{N}^{\circ} 2$ \\ Distribución de vitrales según temática (cifras relativas)}

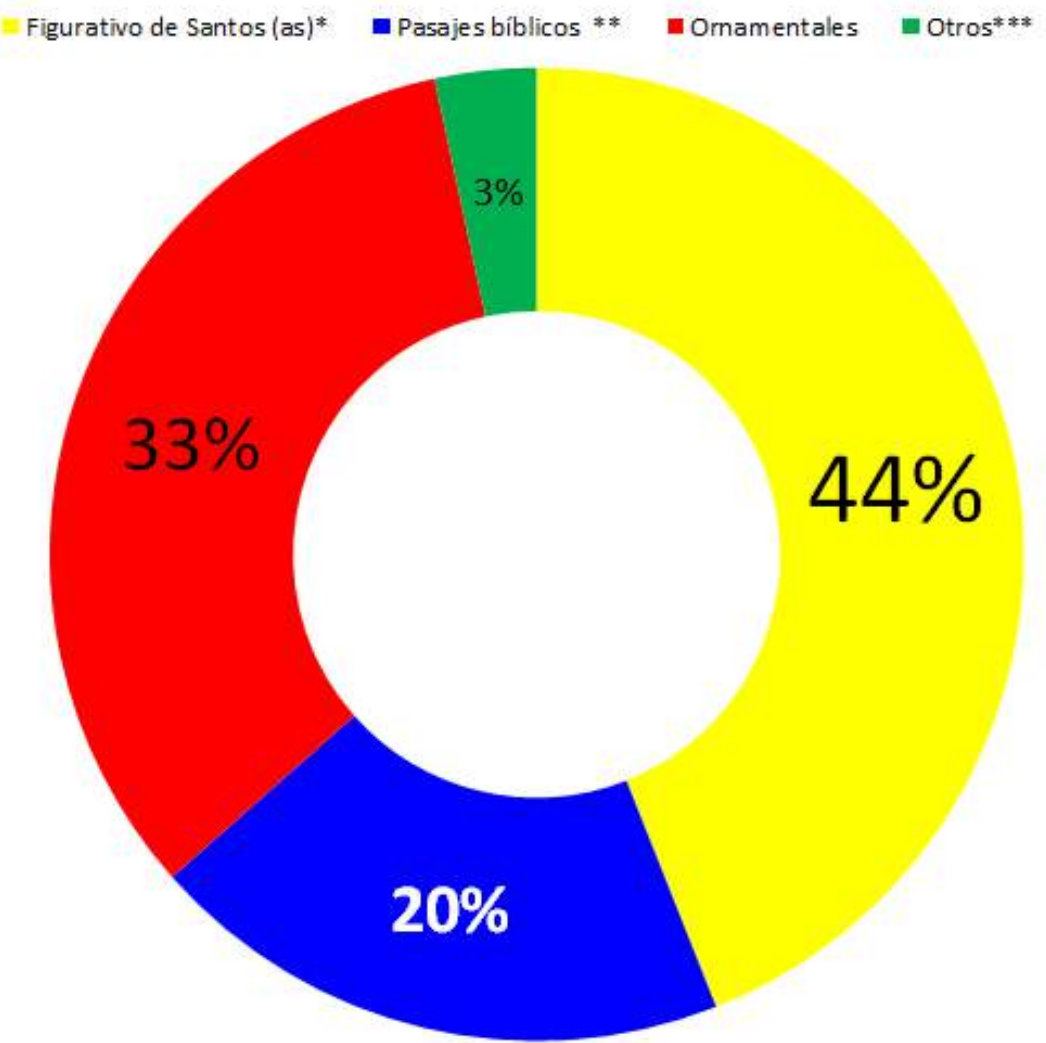

* Las representaciones de la divinidad, como son la Santísima Trinidad y las de cada una de sus personas (tal es el caso del Sagrado Corazón de Jesús), se cuantifican en este rubro pues dentro del imaginario religioso se visualizan con representaciones equivalentes por un amplio grupo de feligreses.

**Se incluyen dos vitrales que representan los dos últimos misterios de gloria del santo Rosario.

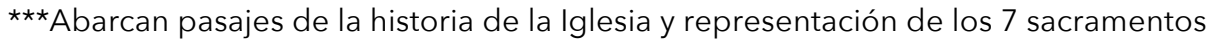

Fuente: Elaboración propia.

Lo anterior, muy probablemente, se encuentra asociado al hecho de que de los ochenta y un vitrales con referencia directa a un episodio bíblico, sesenta y tres de ellos remiten a pasajes de los Evangelios y sólo dieciocho a otros textos del antiguo y nuevo testamento. Se afirma esto pues antes de la Reforma del Concilio Vaticano II, la exposición del pueblo a los textos sagrados era muy limitada, por un lado por el latín en el que se proclamaban los mismos y, por otro, 
debido a la limitada cantidad de perícopas que podían leerse en las celebraciones litúrgicas?.

De las 183 obras que representan figuras de santas y santos, 34 de ellas tienen por tema central a la Santísima Virgen María. Lo cual da cuenta de la centralidad de la visión piadosa de la feligresía en el país y las identidades ligadas a ella.

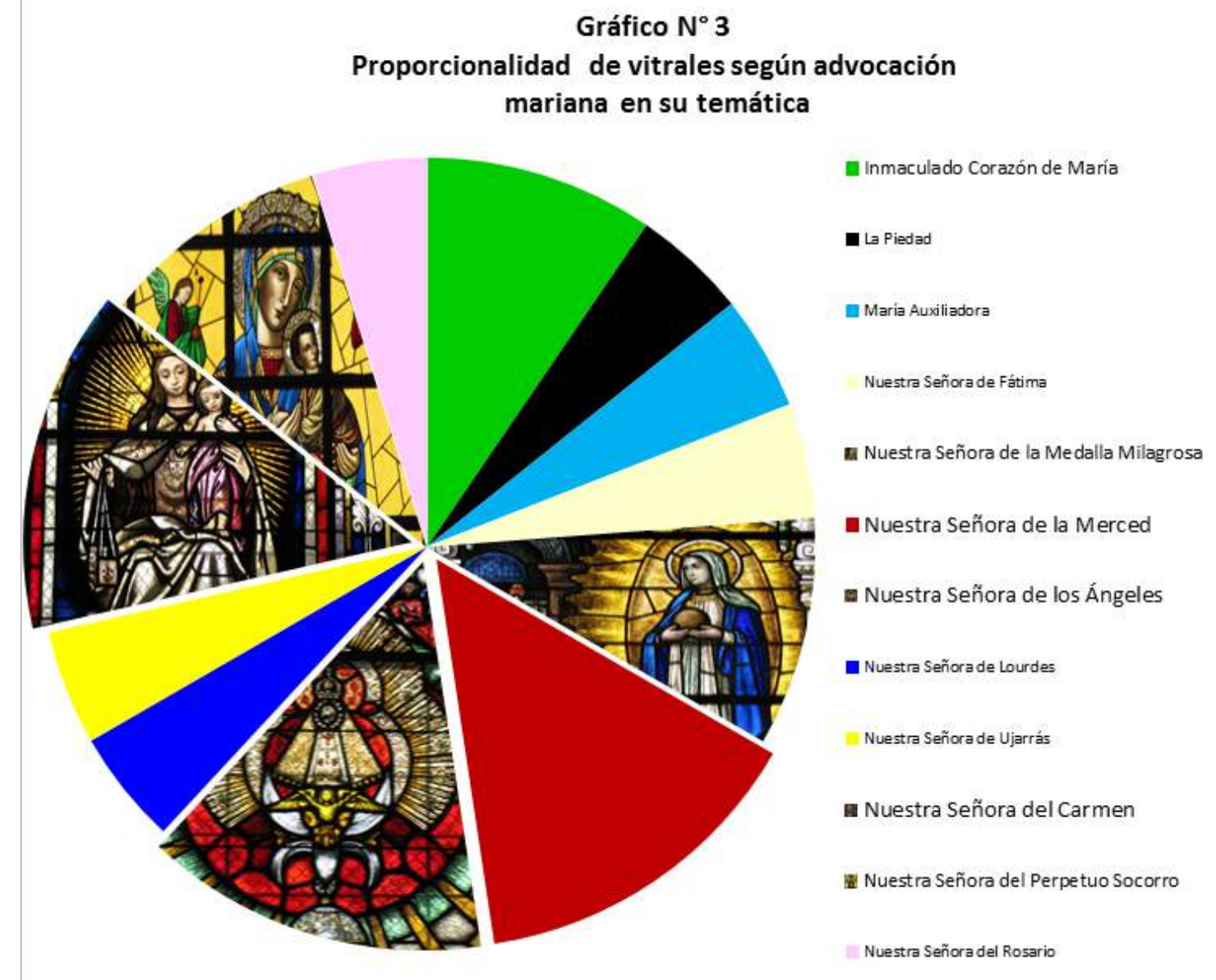

Fuente: Elaboración propia.

Con tema marino existen vitrales únicos en el mundo, tales son los casos de las advocaciones de Nuestra Señora de los Ángeles y el de

9 Por esta razón el numeral 35 de la Constitución Sacrosanctum Concilium afirma: "Para que aparezca con claridad la íntima conexión entre la palabra y el rito en la Liturgia: "En las celebraciones sagradas debe haber lectura de la Sagrada Escritura más abundante, más variada y más apropiada." 
Nuestra Señora de Ujarrás, los tres de la patrona de Costa Rica y el único de la Virgen del Rescate fueron confeccionados por la casa fabricante Tiroler Glasmalerei, estos permiten a su vez captar el ansia de algunos clérigos y poblados de plasmar en los espacios sagrados los rasgos de su idiosincrasia que se entrelazan estrechamente con su fe.

\section{PREGUNTAS MÁS QUE CONCLUSIONES}

Algunas cuestiones que pueden surgir frente a la existencia de este patrimonio material pueden ir desde meras curiosidades, como es el caso de conocer la cantidad de metros cuadrados en vidrio (de muy alto costo monetario en el mercado), inquietudes de carácter práctico asociado al ámbito de la conservación y la protección, como puede ser el estado de los mismos y otras que pueden inquietar acerca de las mentalidades y de los recursos movilizados para alcanzar la ornamentación de los espacios sagrados en los que se han instalado.

Sobre este último aspecto, queda la inquietud de profundizar en el papel que tuvo la mentalidad moderna de dejar marcado un cambio de época por medio de este tipo de técnica, considerando que una técnica de origen medieval fue asumida por los "neo-estilos" arquitectónicos en los cuales se instalaron la mayor parte las vidrieras de las que nos hemos ocupado en esta reflexión.

Por otra parte, para comprender las intenciones y las mentalidades de la época, cabe preguntarse qué movió a las personas donantes a desembolsar dineros para la adquisición de obras de este calibre. Pues, en ello sabemos que juegan motivaciones piadosas, de prestigio social, recordatorio y agradecimiento, pero lo que se desconoce es qué de todo ello pudo primar.

Cabe también cuestionarse qué repercutió más en la toma de decisiones para colocar vitrales: ¿el planteamiento arquitectónico y por consiguiente el criterio de quien diseñó la obra o las ideas y direcciones señaladas por los cura párrocos o algunas otras personas influyentes de la época? Esto puede ayudar a comprender los roles y la configuración del orden social de la época, pues el diálogo y choque de saberes en proyectos tan ambiciosos como estos no son fáciles de eludir. Esto a su vez, puede dar pie a comprender con mayor énfasis 
los liderazgos y el ejercicio del poder desde los centros de población principales y desde los nuevos poblados que se fueron configurando entre el siglo XIX y el siglo XX.

\section{BIBLIOGRAFÍA}

\section{Libros}

Documentos Completos de Vaticano II. (1965) Bilbao: El Mensajero del Corazón de Jesús.

Fonseca, Elizabeth et al. (1998) Historia de la Arquitectura en Costa Rica. San José: Fundación Museos del Banco Central de Costa Rica.

Parroquia San Rafael de Heredia. (1986) Celebración de nuestro centenario parroquial. San Rafael de Heredia.

Sanabria, Víctor Manuel. (1933) Anselmo Llorente y Lafuente. Primer Obispo de Costa Rica (Apuntamientos Históricos). San José: Imprenta Universal.

Zamora, Carlos et al. (2002) Iglesias del Valle Central. San José: Imprenta Nacional de Costa Rica.

\section{Publicaciones periódicas}

Bonilla-Soto, Luis Carlos y Santamaría-Rivera Luis Gerardo. (2016) Levantamiento del inventario de arte sacro, objetos destinados al culto y otras expresiones artísticas de la Arquidiócesis de San José. 2007-2014. En: Espiga. Vol. XV. (Núm. 32) pp. 103-118.

\section{Documentos consultados en Internet}

Díaz, Doriam. (2007) "Inventario revela gran riqueza de vitrales en templos católicos". La Nación. San José. Disponible en: http://www.nacion.com/ocio/artes/Inventario-riqueza-vitrales-temploscatolicos_0_913508667.html Consulta: 03 de octubre 2014.

IFAM. (2003) Cantones productores de café: formación y desafíos actuales. Dirección de gestión municipal - sección de investigación y desarrollo. Disponible en: http://www.hacienda.go.cr/centro/datos/Articulo/Cantones\%20productores \%20de\%20caf\%C3\%A9.pdf. Consulta: 02 de febrero 2016. 
Ruiz, Zaida .(2004) Reseña Histórica de Santo Domingo. Centro de Investigación y Conservación del Patrimonio Cultural. Disponible en: http://www.patrimonio.go.cr/proyectos/inventario/2004\%20IA\%20de\%20San to\%20Domingo,\%20Heredia.html. Consulta: 02 de febrero 2016.

\section{Tesis}

Marín Méndez, Julio. (2011) Templos Parroquiales: similitudes y diferencias. Transformación tipológica a través de un estudio comparativo 1921-1965, 1966-2010. Arquidiócesis de san José. Tesis para optar por el grado de Licenciatura en Arquitectura. San José: Instituto Tecnológico de Costa Rica, Escuela de Arquitectura y Urbanismo.

\section{Informes}

Gutiérrez, Rodolfo y Quesada, Santiago (2006). Informe: Inventario de vitrales de los templos católicos de las provincias de San José y Heredia. San José: Centro de Investigación y Conservación del Patrimonio Cultural. 